\title{
Carcinoma adenóide cístico: revisão da literatura e relato de caso clínico
}

\section{Adenoid cystic carcinoma: review of the literature and case report}

Adriana Terezinha N. N. Alves'; Flávia Dantas Soares²; Arley Silva Junior ${ }^{3}$; Ney Medeiros'; Adrianna Milagres ${ }^{5}$

unitermos

Neoplasia submandibular

Carcinoma adenóide cístico

\section{resumo}

O carcinoma adenóide cístico (CAC) é neoplasia maligna de glândula salivar que acomete principalmente as glândulas parótidas, as submandibulares e as salivares acessórias, sendo raro nas glândulas sublinguais. Com crescimento lento e natureza infiltrativa, clinicamente apresenta-se como nódulo de consistência endurecida. O presente trabalho teve como objetivo revisar a literatura atual sobre o tema em relação aos aspectos clínicos e histopatológicos, bem como relatar um caso de CAC na região submandibular.

\section{abstract}

The adenoid cystic carcinoma (ACC) is a malignant neoplasm of salivary gland that arises preferencially in parotid glands, submandibular and minor salivary glands, but is uncommon in sublingual glands. The ACC is a slow growth and infiltrative tumour that clinically is characterized by a firm mass. The present study aims to rewiew the atually literature of the ACC in relation of clinical and histopathological features and describes a case of ACC in submandibular gland.

\section{key words}

Submandibular neoplasm

Carcinoma adenoid cystic

\section{Introdução}

As neoplasias malignas de glândulas salivares são relativamente incomuns, contabilizando menos de $7 \%$ dos cânceres de cabeça e pescoço. Destes, apenas 10\% foram diagnosticados como carcinoma adenóide cístico (CAC) (2). O CAC ocupa o quinto lugar das lesões epiteliais malignas das glândulas salivares, sendo o carcinoma mucoepidermóide, o adenocarcinoma salivar ou não-específico, o adenocarcinoma de células acinares e o adenocarcinoma polimorfo de baixo grau considerados os quatro mais comuns, em ordem decrescente respectivamente ${ }^{(5)}$.
O CAC origina-se das células ductais e mioepiteliais provenientes dos ductos intercalares ${ }^{(1,4,9)}$. A maioria das lesões se localiza em glândulas parótidas, submandibulares e salivares acessórias, sendo rara nas sublinguais ${ }^{(1,10)}$.

Diversos artigos mostraram uma igual distribuição em relação ao sexo. No entanto, outros relatam ligeira predileção pelo sexo feminino ${ }^{(2,5,8,9)}$. Essa neoplasia acomete mais freqüentemente adultos na quinta, na sexta e na sétima década de vida, sendo incomum em jovens ${ }^{(5,8)}$.

1. Professora de Patologia Oral e Estomatologia da Universidade Cama Filho (UCF) e do Curso de Odontologia da Escola Superior de Ensino Helena Antipoff; mestra em Patologia Oral pela Universidade Federal do Rio Grande do Norte (UFRN).

2. Especialista em Estomatologia pela UCF; mestranda em Patologia Bucodental pela Universidade Federal Fluminense (UFF); professora do Curso de Odontologia da Escola Superior de Ensino Helena Antipoff.

3. Professor de Estomatologia e Semiologia da UGF; especialista em Patologia Oral pela Universidade Federal do Rio de Janeiro (UFR)); mestre em Patologia Bucodental pela UFF; doutorando em Ciências Diagnósticas pela Universidade de Maryland, Baltimore.

4. Professor de Cirurgia Oral da UCF; mestre em Cirurgia Bucomaxilofacial pela UFR).

5. Especialista em Estomatologia pela Universidade do Estado do Rio de Janeiro (UER)); mestranda em Patologia Bucodental pela UFF.

Este trabalho foi realizado no Serviço de Estomatologia e no Departamento de Histologia e Patologia Oral da Faculdade de Odontologia da UCF. 
Tipicamente, o CAC é neoplasia de crescimento lento, apresentando-se clinicamente como aumento de volume ou nódulo de consistência endurecida, recoberto por mucosa íntegra. A ulceração é rara nas lesões de glândulas salivares maiores e nas neoplasias de palato, sendo possível observar superfície ulcerada e, radiograficamente, a destruição óssea ${ }^{(7,8)}$.

A natureza infiltrativa do CAC é responsável pela característica tumoral de disseminação local recorrente, a qual pode ocorrer anos após o tratamento cirúrgico e a radioterapia inicial(12). Metástase à distância é comum, particularmente tardia, sendo o pulmão o sítio mais comumente afetado, seguido de ossos, fígado e cérebro' ${ }^{(2,7,8,12)}$.

Histopatologicamente, o CAC pode expressar-se de forma variável, sendo reconhecidos três padrões principais(1). O padrão cribriforme, o mais clássico, caracteriza-se por ilhas de células epiteliais basalóides, pequenas ou cuboidais, exibindo núcleo extremamente basofílico, com pouco citoplasma e múltiplos espaços císticos lembrando queijo suiço ${ }^{(1,}$ $5,6,8)$. Nesses espaços císticos é possível observar material mucóide basofílico ou produto eosinofílico hialinizado, bem como a combinação de ambos. No padrão tubular, as células epiteliais estão arranjadas em múltiplos ductos, pequenos ou túbulos, envolvidos no estroma hialino e na variante sólida, ilhas ou lençóis que demonstram pouca tendência a formar ductos ou espaços císticos ${ }^{(1,5,6,8)}$. Diferentemente do padrão cribriforme e tubular, no padrão sólido podemos observar pleomorfismo celular e atividade mitótica, bem como focos de necrose nos centros das ilhas das células neoplásicas ${ }^{(5,6,8)}$. A invasão perineural constitui achado comum do CAC, mas não pode ser considerado fator patognomônico, pois também pode ser visto em outras neoplasias de glândulas salivares, como o adenocarcinoma polimorfo de baixo grau ${ }^{(6,9)}$.

As características histopatológicas dessa neoplasia têm sido correlacionadas a sua evolução, sendo a forma tubular a de melhor prognóstico, quando comparada à forma cribriforme, enquanto o tipo sólido apresenta pior prognóstico ${ }^{(7)}$. Outros fatores com considerável valor prognóstico são o sítio primário da lesão, as margens cirúrgicas e a área anatômica invadida ${ }^{(2,4)}$.

\section{Relato do caso clínico}

Paciente do sexo masculino, 60 anos, feodérmico, natural do Espírito Santo, compareceu ao serviço de Estomatologia do Curso de Odontologia da Universidade Gama Filho (UGF), relatando aumento de volume na região submandibular esquerda, com um ano de evolução.

Ao exame físico extrabucal observaram-se massa firme, dolorosa à palpação, e assimetria facial (Figura 1). À inspeção intrabucal, foi evidenciado discreto aumento de volume, recoberto por mucosa íntegra e de coloração normal. O paciente apresentava trismo e relatou anorexia pela dificuldade de alimentação. Exames imagenológicos foram solicitados e a presença de massa tumoral foi confirmada através do auxílio da radiografia panorâmica e da tomografia computadorizada (Figura 2).

Realizou-se biópsia incisional e o material foi encaminhado ao Serviço de Histologia e Patologia Oral da UGF, onde a lâmina foi preparada e corada em hematoxilina e eosina (HE).

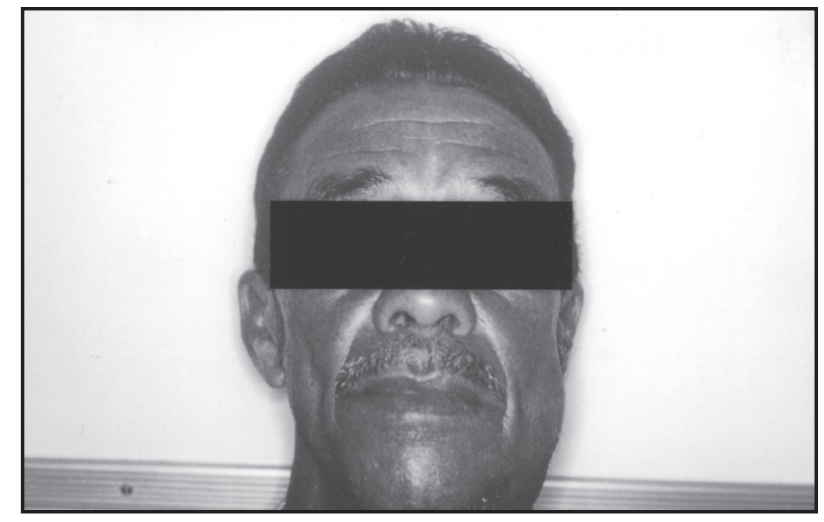

Figura 1 - Exame físico extrabucal: massa firme e dolorosa à palpação do lado esquerdo da face, causando assimetria facial

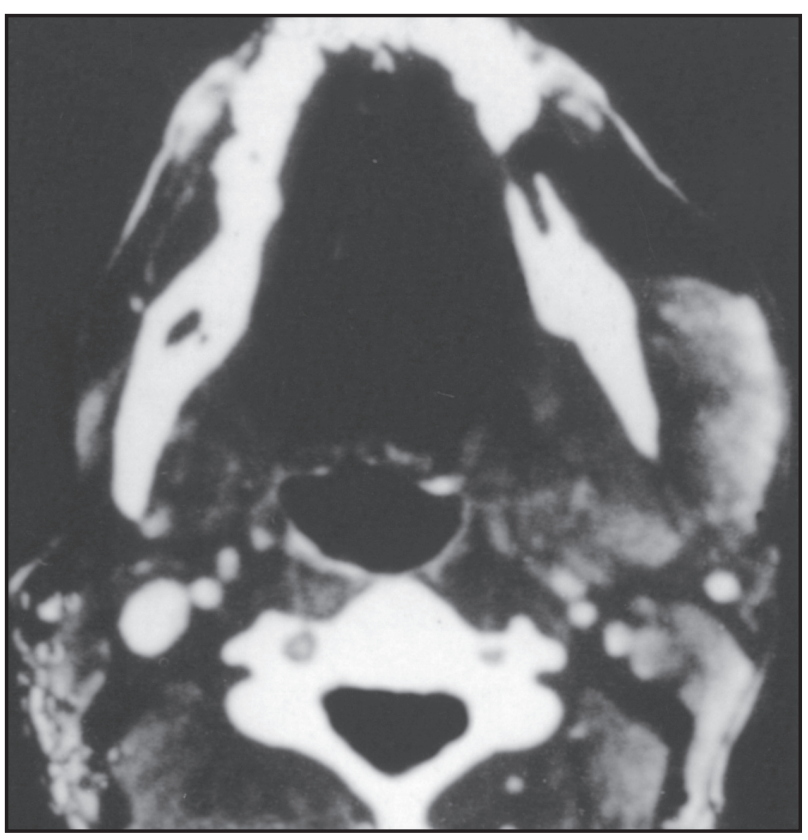

Figura 2 - Tomografia computadorizada: observação da massa tumoral em glândula submandibular esquerda 
Microscopicamente, observou-se um fragmento de neoplasia maligna, originário do epitélio da glândula salivar, apresentando-se sob a forma de ilhas ou ninhos de células tumorais cuboidais pequenas, com núcleo basofílico e pouco citoplasma. Numerosos espaços císticos preenchidos com material hialino ou mucóide também foram identificados (Figuras 3 e 4). Diante do quadro observado, concluímos tratar-se de neoplasia maligna de glândula salivar, sendo o diagnóstico definitivo de CAC.

O paciente foi encaminhado ao Instituto Nacional do Câncer (INCA), onde foi submetido a hemimandibulectomia e tratamento radioterápico adjunto. Atualmente encontrase em acompanhamento clínico periódico.

\section{Discussão}

O CAC representa $14,5 \%$ dos tumores de glândulas salivares e $41 \%$ dos tumores malignos das glândulas maiores e menores ${ }^{(3)}$.

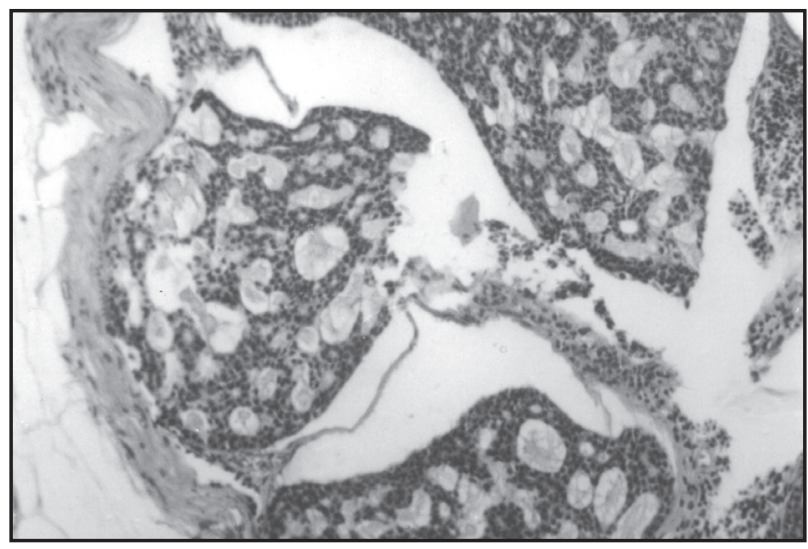

Figura 3 - Aspectos microscópicos: ilhas de células tumorais cubóides pequenas, com núcleo basofílico e pouco citoplasma, caracterizando uma neoplasia maligna originária do epitélio da glândula salivar (HE, 10X)

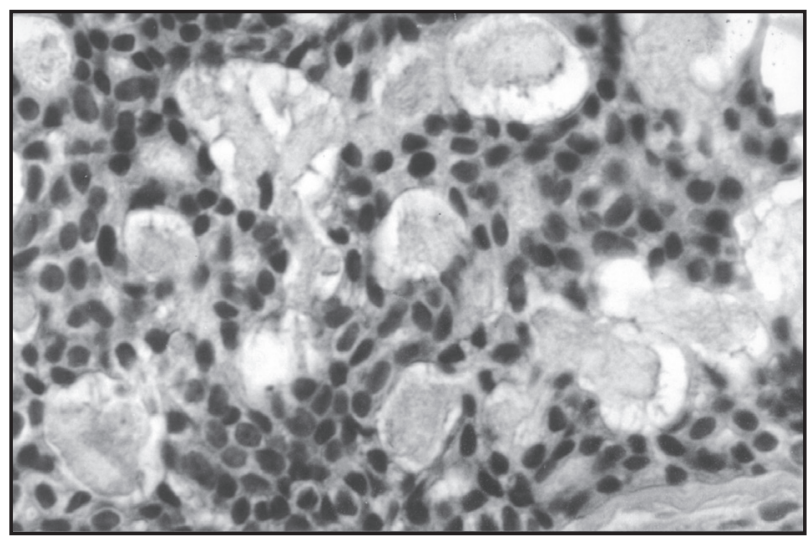

Figura 4 - Aspectos microscópicos: ilhas de células tumorais, com espaços císticos preenchidos com material hialino e mucóide (HE, 40X)
Ostman et al.(9), num estudo epidemiológico na Suécia, concluíram que a localização mais comum foi na glândula parótida, com uma freqüência de $57,5 \%$, seguida das glândulas acessórias, e que as glândulas salivares acessórias são o sítio mais afetado nos adultos ${ }^{(3,12)}$. No caso relatado, a neoplasia maligna se localizava em glândula submandibular esquerda.

O CAC é mais prevalente em adultos, na quinta e na sétima década de vida, sendo incomum em jovens. Apenas $0,6 \%$ dos casos ocorre antes dos 20 anos. Jones et al.(6) descreveram um caso de CAC de palato em um menino de 9 anos; Ustundang et al. ${ }^{(12)}$ relataram um caso na língua de menina de 12 anos; e um caso em glândula sublingual foi diagnosticado por McFall et al. ${ }^{(7)}$, em jovem de 16 anos.

Dados relativos ao aspecto clínico da lesão vêm corroborar aqueles citados pela maioria dos autores que afirma que o CAC apresenta-se como massa tumoral recoberta por mucosa íntegraa ${ }^{(6,7,8)}$. A ulceração e a destruição do osso subjacente podem estar presentes quando a neoplasia origina-se das glândulas menores do palato duro ${ }^{(8)}$.

Segundo Altman et al.(1), 17\% dos pacientes apresentam paralisia do nervo facial e a dor é uma característica de apenas $6,5 \%$ dos casos, mais freqüentemente associada às neoplasias avançadas ou recorrentes ${ }^{(1,8)}$.

O estágio clínico, a localização e o tipo histológico são fatores de importante valor prognóstico ${ }^{(8,12)}$. CAC de seio maxilar e de glândula submandibular têm o pior prognóstico por invadir freqüentemente estruturas adjacentes, além da alta prevalência do subtipo sólido na histopatologia ${ }^{(12)}$. Carcinomas diferenciados, com características tubulares ou cribriformes, como o caso relatado, têm melhor prognóstico que as neoplasias sólidas indiferenciadas ${ }^{(4)}$.

O tratamento de escolha para o CAC é a excisão cirúrgica completa da lesão, com boa margem de segurança, já que a neoplasia é caracterizada por apresentar natureza infiltrativa, responsável pela freqüente recorrência e pela metástase tardia. No presente caso, realizou-se excisão cirúrgica em bloco (hemimandibulectomia). Todos os autores concordam que a dissecção linfática do pescoço deve ser reservada àqueles casos em que se encontra evidência clínica de metástase cervical(7), o que não foi observado em nosso paciente.

Como o CAC é uma neoplasia radiossensível, tratamento radioterápico adjunto foi preconizado. A irradiação pode ser útil no controle da doença microscópica após cirurgia inicial ou no tratamento de recorrência local ${ }^{(5,12)}$.

Shabada et al. ${ }^{(10)}$ obtiveram bons resultados clínicos com o uso do tamoxifeno, um antagonista do receptor de estrogênio, num caso inoperável de CAC recorrente. No 
entanto, não há outro relato na literatura de tal terapêutica para tratamento do CAC.

\section{Considerações finais}

A agressividade biológica do CAC é usualmente subestimada em função do crescimento lento, do isomorfismo e da ausência, praticamente, de atipia celular no tocante ao aspecto histopatológico e aos resultados terapêuticos favoráveis a curto prazo. No entanto, trata- se de neoplasia de pobre prognóstico, e muitos estudos enfatizaram a necessidade de acompanhamento clínico de, no mínimo, cinco anos antes de o paciente ser considerado curado.

\section{Agradecimentos}

Agradecemos a John E. Fogarty, International Center AIDS, International Training Research Program (AITRP).

\section{Referências}

I. ALTMAN, K. W. et al. Pathologic quiz case I. Adenoid cystic carcinoma of the parotid gland. Arch Otolaryngol Head Neck Surg, v. 123, n. 12, p. 1352-5, dec. 1997.

2. BROOKSTONE, M. S. et al. Central adenoid cystic carcinoma of the mandible. J Oral Maxillofac Surg, v. 48, n. 12, p. 1329-33, dec. 1990

3. BROWN, J. A; SWANSON, S. K. Bilateral synchronous renal metastases in a patient 13 years status post resection of adenoid cystic carcinoma of the salivary gland. Urology, v. 5 I n. 2, p. 322-3, feb. 1998

4. COUP, A.; WILLIANSON, J. M.; CURLEY, J. W. Septal, widely infiltrative and clinically occult adenoid cystic carcinoma of the parotid gland. J Laryngol Otol, v. II I, n. 5, p. 49I-2, may 1997.

5. ELLIS, G. L.; AUCLAIR, P. L. Atlas of tumor pathology tumors of the salivary glands. 3. ed. AFIP, I996. p. I55-373.

6. JONES, D. C. E.; BAITON, R. Adenoid cystic carcinoma of the palate in a 9-year-old boy. Oral Surg Oral Med Oral Pathol, v. 69, n. 4, p. 483-6, apr. 1990
7. MCFALL, M. R. et al. Adenoid cystic carcinoma of the sublingual salivary gland in a 16-year-old female: report of a case and review of the literature. J Laryngol Otol, v. III, n. 5, p. 485-8, may 1997

8. NEVILLE, B.W. et al. Patologia oral e maxilofacial. I. ed. Rio de Janeiro: Guanabara Koogan S. A., 1998. p. 346-8.

9. OSTMAN, J. et al. Malignant salivary gland tumours in Sweden 1960- 1989: an epidemiological study. Oral Oncology, v. 33, n 3, p. 169-76, 1997

10. SHABADA, A., GAZE, M. N., GRANT, H. R. The response of adenoid cystic carcinoma to tamoxifen. J Laryngol Otol, v. III, n. 12, p. II86-9, dec. 1997.

I I. TORRE, W.; COMELLAS, M.; CUESTA, M. Massive pleural efusión as isolated manifestation of metastatic spread of salivary adenoid cystic carcinoma. Respir Med, v. 91, n. 3, p. 169-70, 1997

12. USTUNDANG, E. et al. Adenoid cystic carcinoma of the tongue. J Laryngol Otol, v. II4, n. 6, p. 477-80, jun 2000. 